\title{
Use of Facebook Social Media as Product Marketing Media
}

\section{Penggunaan Media Sosial Facebook Sebagai Media Pemasaran Produk}

\author{
Muhammad Anshari Hutasuhut 1); Siti Hazrah 2); Vania Sally Nabila 2); Nurbaiti ${ }^{2)}$ \\ 1,2) Prodi Manajemen, Fakultas Ekonomi dan Bisnis Islam, Universitas Islam Negeri Sumatera Utara \\ Email: ${ }^{1)}$ manshari004@gmail.com; ${ }^{2)}$ sitihazrah.hatta21@gmail.com; ${ }^{2)}$ vaniasally12@gmail.com; \\ 2)nurbaiti@uinsu.ac.id
}

\begin{abstract}
How to Cite :
Hutasuhut, M. A., Hazrah, S., Nabila, V. S., Nurbaiti. (2021). Use of Facebook Social Media as Product Marketing Media. JURNAL EMAK: Jurnal Ekonomi Manajemen Akuntansi Dan Keuangan, 3(1). DOI: https://doi.org/10.53697/emak.v3i1
\end{abstract}

ARTICLE HISTORY

Received [19 Desember 2021]

Revised [27 Desember 2021]

Accepted [1 Januari 2021]

\section{KEYWORDS}

Social Media, Facebook,

Marketing

This is an open access article under the $C C-B Y$-SA license

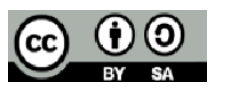

\section{ABSTRAK}

Setiap orang membutuhkan informasi untuk menunjang aktivitas mereka, sehingga berusaha untuk mengakses informasi secepat mungkin. Untuk memperkenalkan produk barang atau jasa yang akan dijual, perusahaan atau usaha kecil dan menengah membutuhkan promosi, dan pola di bidang bisnis melalui facebook atau melalui toko berbasis web sangat menggembirakan. Pencipta menggunakan pendekatan pemeriksaan subjektif yang mencerahkan di mana informasi yang dikumpulkan sebagian besar berupa kata-kata dan kalimat, atau gambar yang lebih penting daripada angka atau frekuensi. Pelaksanaan pemanfaatan media berbasis web Facebook meliputi membangun metodologi data, merencanakan kemajuan dan membangun jaringan dengan menggunakan gathering dan fanspages.

\section{ABSTRACT}

Everyone needs information to support their activities, so try to access information as quickly as possible. To introduce products or services that will be sold, companies or small and medium-sized businesses need promotions, and the pattern in the field of business through Facebook or through a web-based shop is very encouraging. The creator utilizes an enlightening subjective examination approach where the information gathered is predominantly as words and sentences, or pictures that have more significance than numbers or frequencies. Execution of the utilization of Facebook web- based media incorporates building data methodologies, planning advancements and building networks by using gatherings and fanspages.

\section{PENDAHULUAN}

Semua orang membutuhkan data untuk membantu latihan mereka, jadi cobalah untuk mendapatkan data secepat yang diharapkan. Inovasi data tercipta dengan munculnya web dan diikuti dengan hadirnya media berbasis web. Media online adalah media yang memungkinkan setiap orang untuk terhubung dan berbaur dan berbagi tanpa dirusak oleh kenyataan. Media berbasis web menyambut setiap individu yang tertarik untuk mengambil bagian dengan berkontribusi dan memberikan masukan secara lugas, memberikan komentar, dan berbagi data dalam waktu yang cepat dan tanpa batas. (Kaplan, Andreas, dan Haenlein, 2010).

Untuk memperkenalkan produk barang atau jasa yang akan dijual, perusahaan atau usaha kecil dan menengah membutuhkan promosi, Media promosi dapat dilakukan melalui media 
cetak,video, media online atau pun tatap muka secara langsung bertemuka dengan calon konsumen. Kemajuan sebagai kemajuan prosedur yang digunakan untuk mencapai kesepakatan atau mempromosikan tujuan dengan penggunaan praktis, dengan menawarkan manfaat tambahan untuk item atau administrasi baik untuk delegasi dan klien langsung, biasanya tidak dibatasi dalam jangka waktu tertentu (Freddy, 2009:177).

Facebook adalah situs komunikasi orang ke orang di mana klien dapat bergabung dengan jaringan seperti daerah perkotaan, kantor, sekolah, dan lokal untuk bergaul dan berkolaborasi dengan orang lain. Individu juga dapat menambahkan teman mereka, mengirim pesan, dan memperbarui profil mereka sendiri sehingga orang lain dapat melihat tentang mereka. Basuki (1993) menjelaskan bahwa inovasi data merupakan perpaduan dua istilah, yaitu inovasi dan data. Inovasi dicirikan sebagai pelaksanaan ilmu atau tidak dapat dipisahkan dari ilmu terapan. Sedangkan data dicirikan sebagai sesuatu yang dikatakan atau diungkapkan atau berita. Jadi dalam data terjadi pertukaran informasi atau semua yang diketahui. Dengan demikian, inovasi data merupakan inovasi yang digunakan untuk menyimpan, memproduksi, mengolah, dan menyebarkan data yang menggabungkan empat kelas, khususnya numerik, suara, teks, dan gambar. Kehadiran TI menjadi bagian penting dalam memahami zaman penduduk setempat yang maju. Hal ini karena kemajuan mekanis yang ekstrim telah membawa kita ke dunia baru_"cyberspace"_dan secara signifikan mempengaruhi perilaku kita dalam menyampaikan dan berbagi data baik dalam lingkup kecil maupun besar (Autry dan Berge, 2011).

Pola di bidang bisnis melalui Facebook atau melalui toko berbasis web tidak diragukan lagi sangat menggembirakan. Seperti yang ditunjukkan oleh Gemilang (2012) menyatakan bahwa berdasarkan penemuan terakhir oleh ilmuwan ekonomi Morpace, klien Facebook AS menghabiskan rata-rata tiga menit online sekali. Klien berusia 18 hingga 34 tahun menghabiskan rata-rata 8,5 jam berbasis web dan klien berusia 55 tahun ke atas menghabiskan 4,6 jam setiap minggu di Facebook. Konsentrat ini juga menyelidiki tindakan facebook berdasarkan kebangsaan. Seperti yang ditunjukkan oleh hasil, Asia adalah klien Facebook terbesar, karena mereka menghabiskan 39,6\% setiap tujuh hari waktu web mereka di Facebook. Sedangkan Afrika Amerika sebagai klien terbesar kedua dengan 35,1\% dan yang terakhir adalah Hispanik yang menginvestasikan energi minimal di Facebook sebesar 31,7\%. Organisasi Sosial We Are dalam Nasrullah (2015) mendistribusikan hasil penelitiannya bahwa klien media berbasis web dan web di Indonesia sangat tinggi. Ada sekitar 15\% penyusupan web atau 38 juta klien web tambahan. Dari total populasi tersebut, ada sekitar 62 juta orang yang terdaftar dan memiliki akun melalui media berbasis web Facebook. Pemeriksaan tersebut juga menunjukkan bahwa pengguna web biasa di Indonesia menjalani sekitar 3 jam bergaul dan menggunakan media online melalui telepon seluler. Banyaknya jumlah pengguna media sosial di Indonesia tentu saja memunculkan kesempatan untuk mengoptimalkan kehadiran media sosial sebagai media pemasaran produk.

\section{LANDASAN TEORI}

\section{Media Sosial}

"Media online menurut Philip Kotler dan Kevin Keller (2012; 568) dalam (Fauzi, Februari 2016), adalah metode bagi pelanggan untuk berbagi data teks, gambar, suara, dan video satu sama lain dan dengan organisasi serta sebaliknya. sekitar.

Pekerjaan media berbasis web semakin dirasakan dalam membantu pelaksanaan bisnis". "Media berbasis web mengizinkan perusahaan independen untuk mengubah cara mereka berbicara dengan klien, memasarkan barang dan manfaat, serta berkomunikasi dengan klien dengan niat penuh untuk membangun koneksi yang hebat. Abdullah (2012:32) menyatakan bahwa dengan asumsi suatu merek/barang akan dikirim, media berbasis web digunakan untuk menyebarkan data yang diminati untuk dijadikan rekan atau peminat.

2 | Muhammad Anshari Hutasuhut, Siti Hazrah, Vania Sally Nabila, Nurbaiti; Use of Facebook... 


\section{Facebook Marketing}

Facebook didirikan pada tanggal 4 Februari 2004, telah mencatat lebih dari 37 juta klien dan sejumlah besar organisasi bisnis. Facebook telah mengembangkan berbagai macam kegunaan yang dapat diperkenalkan oleh klien. Aplikasi inilah yang meningkatkan nilai Facebook. Banyak aplikasi telah dikembangkan yang membantu bisnis dan pekerjaan seperti menjual atau membeli barang dagangan (Muklason dan Aljawiy, 2011). Perbanyakan organisasi informal, misalnya, Facebook membuka kebebasan yang luar biasa bagi siapa saja untuk berkembang dan dengan harga yang umumnya minimal (Lasmadiarta, 2011). Menampilkan latihan dan proses bisnis lainnya menggunakan organisasi informal Facebook juga dapat disebut sebagai bisnis Internet. Pemasaran Facebook adalah melakukan latihan periklanan dengan menggunakan semua kantor yang diberikan oleh Facebook untuk memperluas (penawaran) dan membangun korespondensi jangka panjang yang serius dengan klien (hubungan klien). Iklan. Facebook melakukan latihan pemasaran menggunakan semua kantor yang disediakan oleh Facebook dengan tujuan penuh untuk memperluas (penawaran) dan membangun korespondensi yang benar-benar langgeng dengan klien (hubungan klien).

\section{METODE PENELITIAN}

Adapun metode penelitian yang dipakai dalam penelitian ini yaitu penelitian kualitatif dengan metode studi literatur. Sumber data yang digunakan dalam penelitian ini adalah data sekunder yang diperoleh dari jurnal citisee.amikompurwokerto.ac.id. Sampel yang diambil yaitu dari study kasus UKM Har's Gordyn. Jalan Raya Desa Rabak Rt.04 Rw.06, Kalimanah, Purbalingga, Jawa Tengah.

\section{HASIL DAN PEMBAHASAN}

Objek dari ujian ini adalah UKM Har's Gordyn. Dengan informasi pelaksanaan pemanfaatan Facebook dalam siklus promosi Gordyn kepada klien Facebook.

\section{Contoh Pesan}

Beberapa hal yang seharusnya dimungkinkan dalam sistem penyampaian pesan iklan harus dimungkinkan dengan lebih banyak cara daripada satu, khususnya:

1. Menyampaikan data asli tentang tirai dan pelapis dekoratif yang tersedia untuk dibeli.

2. Tertanam humor baru dalam pemberitahuan.

3. Berikan foto item dari rencana imajinatif terbaru dari gordyn, dan menarik pembeli.

4. Mengatasi pertanyaan pembeli tentang item naungan secara mendalam.

5. Membujuk pembeli bahwa Har's Gordyn dapat dipercaya dengan memberikan nomor kontak dan email atau Facebook untuk korespondensi sederhana.

6. Produk yang rusak selama pengangkutan dipastikan akan diganti dengan barang baru dengan model dan tema yang sama tanpa dikenakan biaya transportasi.

7. Hal-hal seperti yang tercatat di halaman penggemar.

\section{Media Penyampaian}

Facebook memiliki kantor untuk menyampaikan pesan kepada kliennya, yang dapat melalui kotak pesan (message box), status posting, catatan dan label gambar. Har's Gordyn menggunakan kantor-kantor ini di tempat yang biasa dan tertata, misalnya dengan:

1. Seperti jarum jam mengirim data barang melalui kotak pesan atau email.

2. Ketika tujuh hari membuat catatan yang diidentifikasi dengan manfaat item. 
3. Secara berkala menghasilkan item terbaru sehingga klien secara konsisten

4. memperbarui atau memajukan item sehingga klien tidak merasa lelah dengan model serupa.

5. Secara konsisten membuka saluran bicara Facebook untuk klien yang perlu mendapatkan beberapa informasi tentang item tirai Har.

6. Memasukkan ukuran dan biaya sebagai bahan.

\section{Mengawasi Penyampaian}

Pesan Beberapa cara yang dapat digunakan dalam menyampaikan pesan melalui Facebook agar tersusun dan kadang-kadang adalah sebagai berikut:

1. Berikan Judul atau Subjek pesan yang menarik.

2. Kirimkan pesan sedikit demi sedikit ke klien, tidak massal agar tidak dianggap sebagai spam.

3. Buat pesan sesingkat dan sejelas yang diharapkan.

4. Secara konsisten akhiri dengan kontak.

5. Membuat jadwal dan pengulangan pengiriman pesan secara konsisten.

6. Mentransfer upeti klien yang telah meminta barang di Har's Gordyn sebagai jenis kepercayaan klien.

7. Berikan masukan secepat mungkin agar klien merasa dilayani dengan baik.

\section{Merancang Promosi}

Kemajuan Nuansa Har's gordyn memiliki beberapa cara untuk memajukan, antara lain:

1. Periklanan. Memberikan pesan kepada pelanggan sebagai data barang, sebagai gambar dan penggambaran barang.

2. Individual Deals Exposure. Selling Individual atau Individual Selling akan menjual secara lugas kepada pembeli, hal ini diakhiri dengan berdiskusi langsung dengan pelanggan, baik dengan mengirim pesan atau berkunjung.

\section{Membangun Kelompok}

Orang Dengan mengkonsolidasikan media online ke dalam kerangka periklanan, banyak hal yang dapat dilakukan untuk meningkatkan efektivitas hubungan klien di dewan.

1. Memanfaatkan Group Dan Fans Page. Facebook Gathering dan fanspage atau fan page merupakan bantuan yang diberikan oleh Facebook sebagai halaman yang berisikan data-data umum organisasi/kantor yang dapat disukai (dinikmati) oleh klien Facebook pada umumnya, sehingga klien yang menyukai halaman dirangkai menjadi area lokal kipas. Komunikasi yang terjadi adalah saat pemilik halaman mengirimkan data ke halaman tersebut serta salah satu penggemar mengirimkan data komentar pada halaman tersebut, kemudian pada saat itu semua penggemar yang merupakan individu akan mendapatkan data yang dikirim, jadi ini dianggap sangat menarik untuk iklan. Untuk situasi ini, Har's gordyn membuat halaman penggemar.

2. Optimalisasi Facebook Marketing. Facebook memiliki berbagai macam aplikasi yang dapat dimanfaatkan, termasuk mengadakan pool (survey). Dengan aplikasi survei ini, pengusaha/perkantoran akan mendapatkan masukan (kritik) dari klien secara sembarangan, sehingga konsekuensi dari survei tersebut dapat dimanfaatkan untuk menentukan strategi selanjutnya.

\section{KESIMPULAN DAN SARAN}

Melihat dampak dari pengujian yang telah dilakukan, penulis beralasan bahwa UKM Har's Gordyn memanfaatkan media online Facebook untuk mengiklankan barangnya kepada masyarakat luas. Pencipta melibatkan pendekatan pemeriksaan subjektif grafis sebagai teknik eksplorasi yang digunakan. Pelaksanaan penggunaan itu menggabungkan membangun metodologi data yang menggabungkan desain pesan, media penyampaian dan berurusan dengan penyampaian pesan

4 | Muhammad Anshari Hutasuhut, Siti Hazrah, Vania Sally Nabila, Nurbaiti; Use of Facebook... 
yang diberikan. Kemudian, pada saat itu, merencanakan kemajuan termasuk membuat promosi dan ekspos kepada orang- orang. Kemudian, pada saat itu, kumpulkan area lokal dengan menggunakan pertemuan dan halaman penggemar melalui Facebook dan meningkatkan tampilan Facebook melalui aplikasi.

\section{DAFTAR PUSTAKA}

Agus Triyono (2011). Pengaruh situs jejaring sosial facebook sebagai media alternatif untuk promosi. Jurnal Dian Vol 11. 1-11

Autry, Alex J dan Berge Zane. 2011. Digital Natives and Digital Immigrants: getting to know each other. USA: Emerald Group Publishing Limited.

Gemilang, Dian Ayu. 2012. Peran Facebook sebagai Media Komunikasi Bisnis Online (Studi Deskriptif Kualitatif Peran Facebook sebagai Media Komunikasi Bisnis Online). Fakultas IImu Sosial dan IImu Politik Program Studi IImu Komunikasi. Skripsi. Universitas Pembangunan Nasional "Veteran" Jawa Timur.

Kaplan, Andreas M and Michael Haenlein. Users of the world, unite!

The challenges and opportunities of Social Media, 2010.

Nasrullah, Rulli. 2015. Media Sosial; Persfektif Komunikasi, Budaya, dan Sosioteknologi. Bandung : Simbiosa Rekatama Media.

Febriyanti. E; Rifai. Z; Hasanah. S. N; Wijayanti. D. F; Suhening. L;Frastika. L. (2017).Pemanfaatan Media Sosial Facebook Sebagai Media Pemasaran Produk. ISBN: 978-602-60280-1-3.. 